\title{
INVESTIGATING THE DRIVER'S RESPONSE TIME AT SIGNALIZED INTERSECTIONS
}

\author{
Pelin Çalişkanelli, Serhan Tanyel \\ Dept of Civil Engineering, Dokuz Eylül University, Turkey
}

Submitted 8 December 2014; resubmitted 27 February 2015, 1 July 2015; accepted 31 December 2015; published online 14 November 2016

\begin{abstract}
It is generally accepted that, behavioural variables may show differences in different countries, and sometimes in different regions depending on cultural and other socio-economic factors. In literature, several researchers have emphasized that performance of signalized intersections is highly related with drivers' behaviour. However, only a few parameters can be used to reflect drivers' behaviour in performance analysis. Start response time is used as a key parameter in calibration of analytical and simulation models. In this study, a detailed analysis is conducted on the variability of start response time with respect to parameters like those that manoeuvre type, cycle time, gender of drivers', etc. by using data obtained from signalized intersections in İzmir, Turkey. Analysis showed that left and right turning drivers have slightly shorter start response times than all through passing vehicles. In addition, the effect of start response time on base saturation flow is discussed.
\end{abstract}

Keywords: signalized intersections; headway; start response time; saturation flow; lognormal distribution; regression analysis.

\section{Introduction}

In urban highway transportation systems, signalization is mostly utilized in the management of intersections. A well-designed signalization system can provide many advantages such as both the ensuring of pedestrian and vehicle safety and the enhancement of intersection capacity. The driving habits of drivers, vehicle following behaviour, lane changing habits, regional factors and the precision on traffic rules may be accepted as some of the important elements that influence the signalized intersection capacity. However, only a few parameters can be used to reflect the effect of drivers behaviour on capacity and performance of signalized intersections. Base saturation flow can be assumed as the most important one among others.

Saturation flow can be defined as the number of vehicles likely to pass through a lane when there is a continuous queue in a single lane and when the signal has been green for an hour (Highway Capacity Manual 2010). Saturation flow is a concept that is hard to define due to the difficulties in determining the vehicles exposed to start-up delay. It is generally expected that during the discharge of a queue, headway between vehicles decreases as of the second vehicle and remains stable as of the 4 th or 5 th vehicle. This value, accepted to remain stable between the vehicles and used to determine the maximum number of vehicles likely to pass through the intersection within an hour, is called saturated headway. Depending on the saturated headway, the saturation flow value can be computed as:

$$
S=\frac{3600}{h_{s}}
$$

where: $S$ is the saturation flow [vehicles/h]; $h_{s}$ is the average saturated headway [sec].

In literature, several researchers have emphasized that saturation flow is highly related with drivers' response times (Akçelik et al. 1999; Bonneson 1992; Long 2005; Li, Prevedouros 2002; Tong, Hung 2002). Simply start response time can be defined as the average driver response time for the first vehicle to start moving at the start of the displayed green periods. Akçelik et al. (1999) defined the relationship between saturation headway and start response time of the leading vehicle in the queue as follows:

$$
h_{s}=t_{r}+d_{a}-t_{s}
$$

where: $t_{r}$ is the start-response time of the leading vehicle in the queue [sec]; $d_{a}$ is the acceleration delay [sec]; $t_{s}$ is the start-up lost time [sec]. 
Various researchers have suggested different values for start response time of drivers. Institute of Transportation Engineers (ITE 1994) assumed a value of $1.0 \mathrm{sec}$ for signalized intersections. Akçelik et al. (1999) has also used $1.0 \mathrm{sec}$. Clement et al. (2004) used $0.9 \mathrm{sec}$ in their calculations. Bonneson (1992) suggested $1.22 \mathrm{sec}$ for start response time. Li and Prevedouros (2002) found mean values for through and left turning vehicles as 1.76 and $1.42 \mathrm{sec}$ respectively. In AIMSUN simulation program, start response time value is assumed as $1.35 \mathrm{sec}$ for the leading vehicles in a queue (TSS 2010). Tong and Hung (2002) suggested $1.32 \mathrm{sec}$ for passenger cars and taxis. On the other hand, in AASHTO it is stated that this value may change between $1.0-2.5 \mathrm{sec}$, considering different situations a driver may face (Roess et al. 2010).

Messer and Fambro (1977) suggested $1.0 \mathrm{sec}$ for drivers' response times except for the vehicle in the first position of the queue. They stated that the leading driver's response time has an additional delay of $2.0 \mathrm{sec}$ (Bonneson 1992).

Many parameters like geometry of an approach (lane width, number of lanes etc.), cycle length, duration of red or green phases, manoeuvre type (left or right turning) etc. may have a significant effect on start response times. For example, in Highway Capacity Manual (2010) it is stated, that narrow lanes have a negative impact on saturation flow rate and wide lanes allow an increase on traffic flow. This statement shows that, start response times of drivers may also change due to lane width. Similarly long cycle lengths and/or red phase durations may increase the impatience of drivers. This may result with relatively shorter start response times. On the other hand, demographic parameters (income, age, gender etc.) are found to have an important impact on drivers' response times. Mehmood and Easa (2009) have suggested an empirical model for acceleration/ deceleration reaction times of drivers, which contain gender and age as important components. Although the effect of gender may be difficult to be put in use in traffic flow models, several researchers tried to include gender differences in traffic flow analysis. For example, Qu et al. (2014) suggested a model for calculation of follow-up times at roundabouts in which gender is a model parameter. Differences between female and male drivers are widely being analysed in traffic safety researches (Sivak, Schoettle 2011; SIRC 2004).

This study aims to make a discussion on the effect of start response time based on the saturation flow and performance of signalized intersections. For this purpose, start response time data was collected at nineteen approaches of nine different signalized intersections in İmir, Turkey. Relation between start response times and parameters like signal timing and traffic management features (number and width of approach lanes, etc.) are tried to be modelled by using linear regression to reflect their effect on drivers' performance. Differences between male and female drivers are also tried to be emphasized in the present study.

\section{Observation Studies}

Data was collected at nine isolated signalized intersections found in Izmir, Turkey. The number of lanes, lane width, lane usage types and cycle durations of intersections under examination are presented in Table 1. The observed intersections were selected considering their following features:

- the intersections are located on important arterials with a high traffic load;

- observations are made at morning or/and evening peak hours during typical weekdays at approaches with high traffic demand;

- the longitudinal grade value in the approach lanes of the intersections is smaller than $1 \%$;

- parking is not allowed in approach lanes especially at the peak hours observed;

- there is no bus stop at a distance likely to affect the movements of vehicles at signal points;

Table 1. Information about the intersections

\begin{tabular}{|c|c|c|c|c|}
\hline $\begin{array}{l}\text { Name of the } \\
\text { intersection }\end{array}$ & $\begin{array}{c}\text { Volume } \\
\text { [veh/h/lane] }\end{array}$ & $\begin{array}{l}\text { Approach } \\
\text { name }\end{array}$ & $\begin{array}{l}\text { Lane } \\
\text { type }\end{array}$ & $\begin{array}{l}\text { Cycle } \\
\text { [sec] }\end{array}$ \\
\hline Tansaş Int. & 575 & Konak & $3 \mathrm{TR}$ & 75 \\
\hline \multirow{4}{*}{ Boğaziçi Int. } & 508 & Basmane & TR & \multirow{4}{*}{80} \\
\hline & 213 & Otogar & $\mathrm{LT}$ & \\
\hline & 322 & \multirow{2}{*}{ Boğaziçi } & LT & \\
\hline & 394 & & RT & \\
\hline \multirow{3}{*}{ Göztepe-1 Int. } & 418 & Üçkuyular & $\mathrm{TR}^{*}$ & \multirow{3}{*}{70} \\
\hline & 520 & Konak & $\mathrm{TR}^{\star}$ & \\
\hline & 600 & Sahil & 1LT-RT* & \\
\hline \multirow{3}{*}{ Göztepe-2 Int. } & 545 & Konak & $\mathrm{TR} \mathrm{RT}^{\star}$ & \multirow{3}{*}{70} \\
\hline & 430 & $\ddot{\ddot{T}} \quad$ l & TR & \\
\hline & 269 & Uçkuyular & LT & \\
\hline \multirow{4}{*}{$\begin{array}{l}\text { Buca } \\
\text { Koop-Girişi-1 } \\
\text { Int. }\end{array}$} & 1356 & \multirow{2}{*}{ Otoyol } & $2 \mathrm{TR}$ & \multirow{4}{*}{85} \\
\hline & 582 & & LT & \\
\hline & 475 & \multirow{2}{*}{ Buca } & RT & \\
\hline & 1110 & & TR & \\
\hline \multirow{6}{*}{$\begin{array}{l}\text { Buca } \\
\text { Koop-Girişi-2 } \\
\text { Int. }\end{array}$} & 946 & \multirow{2}{*}{ Otoyol } & TR & \multirow{6}{*}{85} \\
\hline & 774 & & TR/LT & \\
\hline & 140 & \multirow{2}{*}{$\begin{array}{l}\text { Buca } \\
\text { Koop. }\end{array}$} & LT & \\
\hline & 80 & & RT & \\
\hline & 774 & \multirow{2}{*}{ Buca } & TR & \\
\hline & 633 & & TR/RT & \\
\hline \multirow{6}{*}{$\begin{array}{l}\text { Dokuz Eylül } \\
\text { Rektörlük Int. }\end{array}$} & 120 & \multirow{2}{*}{ Lozan } & RT & \multirow{6}{*}{70} \\
\hline & 470 & & LT & \\
\hline & 264 & Gündo ădu & TR/RT & \\
\hline & 655 & Gundogau & TR & \\
\hline & 731 & Konolr & TR/RT & \\
\hline & 857 & Konak & TR & \\
\hline MKS & 1186 & Konak & $3 \mathrm{TR}$ & 70 \\
\hline $\begin{array}{l}\text { Bulvarı-Giriş } \\
\text { Int. }\end{array}$ & 690 & Üçkuyular & $3 \mathrm{TR}$ & 70 \\
\hline
\end{tabular}

Note: ${ }^{*}$ indicates single lane approach. 
- minimum 25 cycles were observed for each approach lane examined at the intersections observed;

- there is no downstream queue or pedestrian mobility to impede the discharge of the queue.

Start response time is the time between the start of the displayed green time and the first movement of the leading vehicle in the queue. For this purpose, a video camera was located at a higher building where both traffic signals and leading vehicle could be observed. In addition, an observer was located in alignment with the signal and the leading vehicle, which recorded the start response time with a stopwatch.

The authors are aware that instrument errors were unavoidable. It should be stated that, the observations from video recordings are quite sensitive to the timing precision of the video frame rate. To overcome this problem, as presented in the study of $\mathrm{Li}$ and Prevedouros (2002), the data was collected from the field by using a stopwatch and all the video recordings were watched and data was extracted from the recordings also. By this way, the data obtained from both sources were crosschecked in order to obtain an accurate data set and the biases are minimized due to different perceptions of multiple observers.

Data of a vehicle type, green and red phase durations and cycle lengths, lane widths and types (kerb, middle or median lane), manoeuvre type (left, right turning or through passing vehicles) and gender of the driver were also recorded for each observed response time values. A total of 1788 start response times of leading drivers in queues are obtained.

\section{Queue Discharge Headways}

As known, the drivers of the vehicles in the first line of the queue are exposed to delay more than the vehicles waiting in more rear lines of the queue as they will decide to start moving by observing the signal change. In Turkey, Calışkanelli (2010) has stated that, in contrast with previous research, the headway values did not show the expected tendency to decrease upon an increase in the queuing position. Her analyses demonstrate that the headway values obtained depending on the behaviours of Turkish drivers when leaving the signal should be evaluated differently from the generally accepted methods. Results of her study showed that the headway values do not show any statistically significant decrease depending on the queuing position in İzmir, Turkey. In line with these calculations, it is considered appropriate to obtain the average headways of all vehicles as of the second line of the queue to determine the average saturated headway values and to determine the saturation flow depending on the average saturated headway values found.

Jin et al. (2009) tried to model queue discharge headways in Beijing. They have found that, when the departure headways for each position are analysed individually they all follow a certain lognormal distribution. Calışkanelli (2010) in her study, preferred a similar approach and she tried to fit an appropriate distribution for headways in each position including the 1st vehicles' in the queue. She also found that, lognormal distribution is the best distribution, which can be used in modelling queue discharge headways. Probability density function of lognormal distribution can be written as (Luttinen 1996):

$$
f\left(\frac{t}{\tau}, \mu, \sigma\right)=\frac{1}{\sigma(t-\tau) \cdot \sqrt{2 \cdot \pi}} \cdot e^{\left(-\frac{(\ln (t-\tau)-\mu)^{2}}{2 \cdot \sigma^{2}}\right)}, t>\tau,
$$

where: $\mu$ is mean deviation; $\sigma$ is standard deviations; $\tau$ is the location parameter of a headway distribution.

In the study, first of all, it was intended to determine from which vehicle in the queue the saturated flow regime began, considering the queue discharge headways. For this purpose, data sets from four approaches of three intersections (Tansaş, Dokuz Eylül Rektörlük and MKS Bulvarı-Giriş) are used. Mean and standard deviation values for queue discharge headways of each queue position are presented in Table 2. The headway values collected in each cycle were grouped based on lanes as the average headways of the vehicles in the 1st line of the queue until the 8 th line of the queue (1st, $2 \mathrm{nd}$, $3 \mathrm{rd}, \ldots, 8$ th line of the queue).

Table 2. Average and standard deviation of the headways of the queuing vehicles

\begin{tabular}{|c|c|c|c|c|c|c|}
\hline \multirow{2}{*}{$\begin{array}{c}\text { Queueing } \\
\text { No }\end{array}$} & \multicolumn{2}{|c|}{ Curb } & \multicolumn{2}{c|}{ Middle } & \multicolumn{2}{c|}{ Median } \\
\cline { 2 - 7 } & $\mu$ & $\sigma$ & $\mu$ & $\sigma$ & $\mu$ & $\sigma$ \\
\hline 1 & 3.31 & 0.78 & 3.40 & 0.89 & 3.07 & 0.94 \\
\hline 2 & 2.56 & 0.78 & 2.31 & 0.71 & 2.31 & 0.77 \\
\hline 3 & 2.34 & 0.56 & 2.38 & 0.67 & 2.37 & 0.71 \\
\hline 4 & 2.40 & 0.75 & 2.30 & 0.86 & 2.30 & 0.26 \\
\hline 5 & 2.31 & 0.69 & 2.11 & 0.74 & 2.23 & 0.66 \\
\hline 6 & 2.28 & 0.74 & 2.14 & 0.84 & 2.24 & 0.75 \\
\hline 7 & 2.26 & 0.78 & 1.98 & 0.81 & 2.27 & 0.68 \\
\hline 8 & 2.45 & 0.99 & 2.16 & 0.81 & 2.37 & 0.77 \\
\hline
\end{tabular}

The ANalysis Of VAriance (ANOVA) was applied to the grouped headway data in order to find from which vehicle in the queue the saturated regime started. Starting from the 1st vehicles in the queue, a group was formed using the vehicles in the related line of each lane and it was investigated whether the group averages were different from each other.

The null hypothesis proposed to determine the line where the saturated regime starts is that the average headway values of the vehicles belonging to each line are equal. With $\mu_{i}$ denoting the average headway of the vehicle in the $i$-th line of the queue, the null hypothesis was established to state that $\mu_{i}$ 's $(i=1, \ldots, 8)$ were equal, while the alternative hypothesis was established to state that at least one of the $\mu_{i}$ 's (or averages) was different:

$H_{0}: \mu_{1}=\mu_{2}=, \ldots, \mu_{8}$ 'the headway averages of the vehicles in the 1 st, $2 \mathrm{nd}, 3 \mathrm{rd}, \ldots, 8$ th lines of the queue are equal;

$H_{1}$ : at least one is different. 
Whether the averages were different from each other was determined with the $F$-test. The values computed were evaluated for the significance level of 0.05 . If the probability values computed in the analyses are smaller than $0.05, H_{0}$ hypothesis is rejected. The probability values computed in the analyses were indicated with letter ' $p$ '. In the light of the above-mentioned remarks:

$H_{0}$ is rejected for $p<0.05$ and

it is failed to reject $H_{0}$ for $p>0.05$.

At the first stage of the analyses, the headway averages of the vehicles in each line of the queue were examined altogether. When all vehicles were examined altogether, whether the average of the headways of the vehicles waiting in each line of the queue would be considered equal was tested according to the significance level of 0.05 . As a result of the analysis, $H_{0}$ hypothesis was rejected for all data groups. At the second stage of the analyses, the vehicles in the 1st line of the queue were excluded from the computations. When the average headways as of the vehicles in the 2nd line of the queue were examined altogether, it was failed to reject $H_{0}$ hypothesis for all data groups. The $F$-values computed and the $p$-values computed depending on these values are given in Table 3 . When Table 3 is examined, it is seen that there is no significant difference in the headway averages as of the second vehicle in the queue. This shows that only the average headway values of the vehicles in the 1st line differed from the other averages and that the headway averages of the vehicles in the 2nd, 3rd, ..., 8th lines might be considered the same.

By using lognormal distribution, cumulative probability graphs of headways for each queue position can be plotted (Figs 1-3). From the figures, Turkish drivers' behaviour difference can be observed more clearly. Headways of the 1st vehicles in the queue are greater than other vehicles in the rear queue positions as expected. However, as stated above, no significant difference can be seen between headways of vehicles at the 2 nd and higher queue positions. This difference is probably based on start response times of leading drivers.

\section{Analysis on Start Response Times of Leading Vehicles in the Queue}

As stated above, start response time of leading drivers in a queue may have a significant effect on the performance of signalized intersections. However, there is confusion in the usage of terms 'reaction time' and 'response time'. The Hick-Hyman 'law' expresses a relationship between the number of alternatives that must be sorted out to decide on a response and the total reaction time, that is, that lag in time between detection of an input (stimulus, in this study the instant when red light turns to green) and the start of initiation of a control (when the vehicle starts to move/accelerate) or other response. If the time for the response itself is also included, then the total lag is termed 'response time.' Thus, it should be noted that, reaction is always a part of the response time (Koppa 2001).

Table 3. Results of the F-test for the queuing groups

\begin{tabular}{|c|c|c|c|c|c|c|c|}
\hline & \multicolumn{2}{|c|}{ Curb Lane } & \multicolumn{2}{|c|}{ Middle Lane } & \multicolumn{2}{|c|}{ Median Lane } \\
\hline & & $\begin{array}{l}\text { All vehicles } \\
\text { in the queue }\end{array}$ & $\begin{array}{l}\text { Queued vehicles } \\
\text { (except first one) }\end{array}$ & $\begin{array}{l}\text { All vehicles } \\
\text { in the queue }\end{array}$ & $\begin{array}{l}\text { Queued vehicles } \\
\text { (except first one) }\end{array}$ & $\begin{array}{l}\text { All vehicles } \\
\text { in the queue }\end{array}$ & $\begin{array}{l}\text { Queued vehicles } \\
\text { (except first one) }\end{array}$ \\
\hline \multirow{2}{*}{$\begin{array}{l}\text { Queued } \\
\text { vehicles }\end{array}$} & $H_{n}$ & 2.517 & 2.376 & 2.835 & 2.213 & 2.407 & 2.298 \\
\hline & $\begin{array}{l}\text { Standard } \\
\text { deviation }\end{array}$ & 0.7533 & 0.739 & 0.792 & 0.774 & 0.767 & 0.734 \\
\hline \multicolumn{2}{|c|}{$F$-value } & 24.170 & 1.290 & 12.930 & 1.190 & 16.190 & 1.170 \\
\hline \multicolumn{2}{|c|}{$p$-value } & 0.000 & 0.263 & 0.000 & 0.310 & 0.000 & 0.321 \\
\hline \multicolumn{2}{|c|}{$H_{0}$} & rejected $(X)$ & accepted & rejected $(X)$ & accepted & rejected $(X)$ & accepted \\
\hline
\end{tabular}

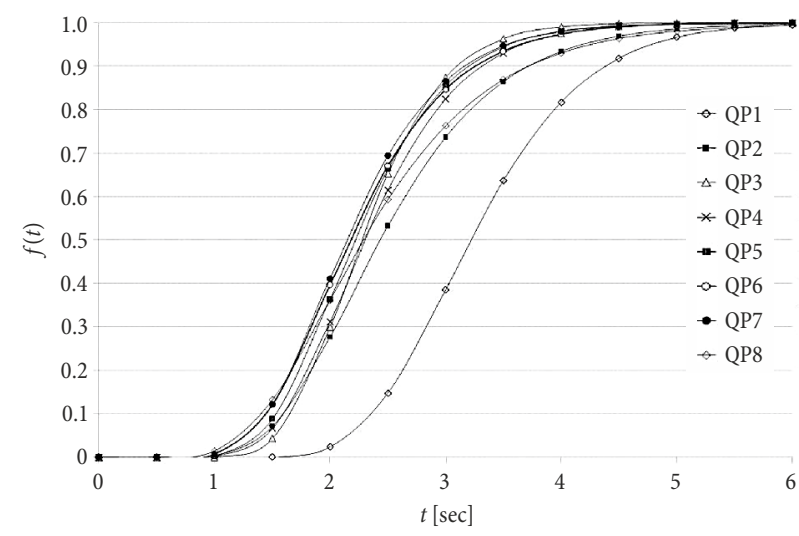

Fig. 1. Cumulative distribution plots of headways for curb lane

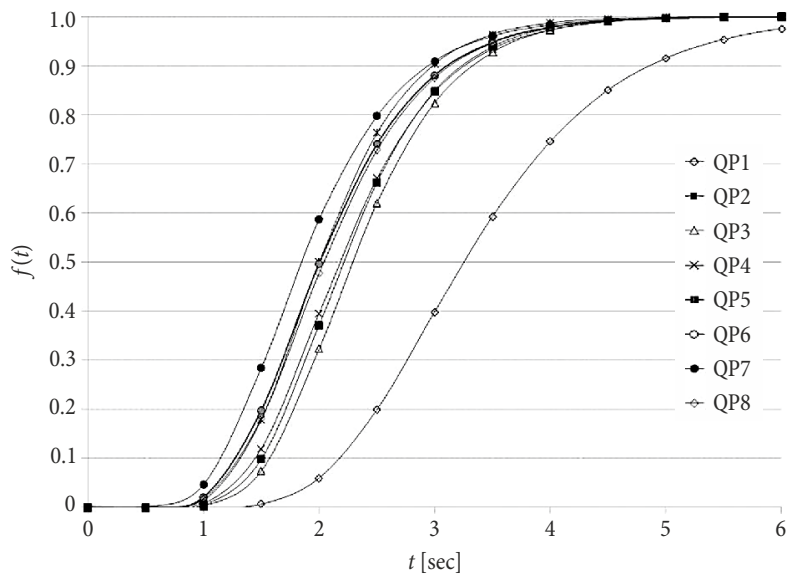

Fig. 2. Cumulative distribution plots of headways for middle lane 


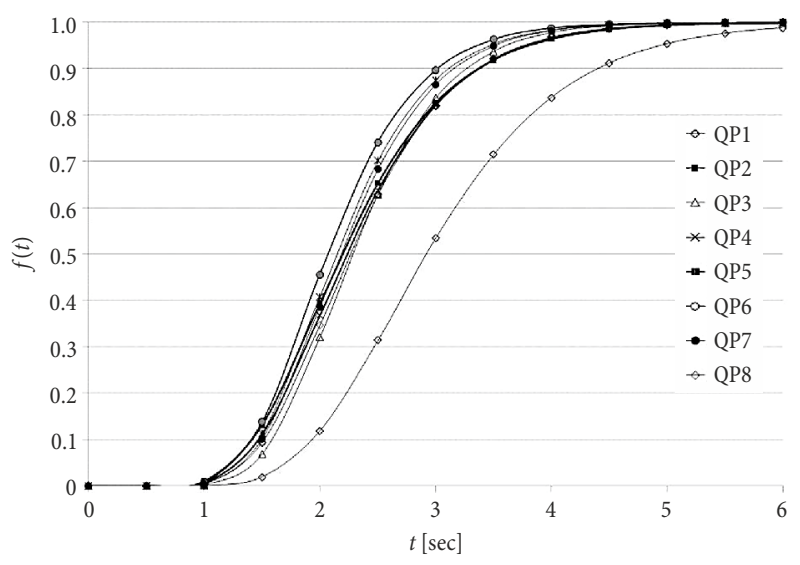

Fig. 3. Cumulative distribution plots of headways for median lane

In this study 1788 start response times of leading drivers in queues are obtained from nine isolated signalized intersections. Collected data consist of passenger cars. Passenger car data group is also categorized according to the manoeuvre type (through passing, right or left turning vehicles) and gender of the drivers (Table 4).

Table 4. Information about the start response time

\begin{tabular}{|c|c|c|c|c|c|}
\hline \multicolumn{3}{|c|}{ Vehicle type } & $\begin{array}{l}\text { Number of } \\
\text { observations }\end{array}$ & $\begin{array}{l}\text { Average } \\
\text { [sec] }\end{array}$ & $\begin{array}{l}\text { Standard } \\
\text { deviation }\end{array}$ \\
\hline \multirow{4}{*}{ 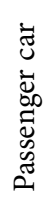 } & \multirow{2}{*}{$\begin{array}{l}\text { Through } \\
\text { passing }\end{array}$} & male & 798 & 1.44 & 0.86 \\
\hline & & female & 173 & 1.70 & 1.00 \\
\hline & \multicolumn{2}{|c|}{ Left turning } & 300 & 1.26 & 0.77 \\
\hline & \multicolumn{2}{|c|}{ Right Turning } & 200 & 1.39 & 0.57 \\
\hline
\end{tabular}

From Table 4 it can also be seen that the start response times of left and right turning drivers are lower than of the through passing drivers. This result is consistent with the results obtained by $\mathrm{Li}$ and Prevedouros (2002). Another important outcome of the analysis is, female drivers' start response times are higher than male-drivers.
To emphasize the difference between manoeuvre data, descriptive statistics of left, right turning and through passing drivers' response times are given in Table 5. In Fig. 4, probability distribution plots of left turning, right turning and through passing drivers and in Fig. 5 probability distribution plots of male and female drivers' response times are shown. A hypothesis test is performed to determine whether the average response times of right or left turning and through passing drivers are statistically equal. Hypothesis test shows that they are significantly different from each other $(F$-value $=8.32$, $p$-value $=0.000$ at $95 \%$ confidence level). Similarly, another single factor ANOVA test is carried to determine whether the average response times of male and female drivers are statistically equal. Result of the test shows that they are significantly different from each other $(F$-value $=11.99, p$-value $=0.001$ at $95 \%$ confidence level $)$.

Table 5. Descriptive statistics of left, right turning and through passing drivers' response times

\begin{tabular}{|l|c|c|c|c|c|}
\hline \multicolumn{1}{|c|}{$\begin{array}{c}\text { Manoeuvre } \\
\text { type }\end{array}$} & Mean & $\begin{array}{c}\text { Standard } \\
\text { deviation }\end{array}$ & Variance & Skewness & Kurtosis \\
\hline $\begin{array}{l}\text { Through } \\
\text { passing }\end{array}$ & 1.48 & 0.89 & 0.80 & 2.61 & 11.22 \\
\hline Left turning & 1.26 & 0.77 & 0.60 & 2.56 & 10.36 \\
\hline Right turning & 1.39 & 0.57 & 0.32 & 0.97 & 0.74 \\
\hline
\end{tabular}

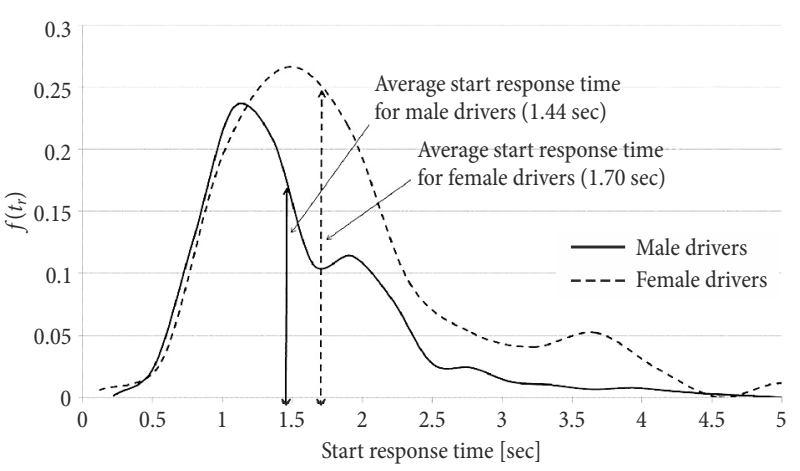

Fig. 5. Probability distribution plots of male and female drivers' response times

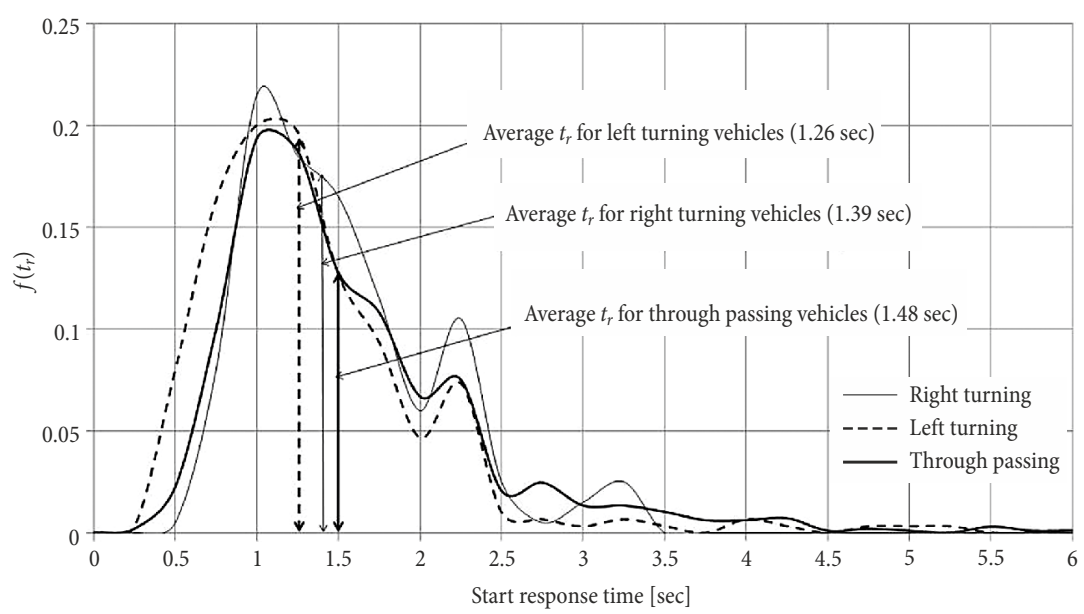

Fig. 4. Probability distribution plots of left turning, right turning and through passing drivers' response times 
When Figs 4, 5 and Table 5 are considered together it is clear that, all data groups are skewed to the right. This shows that, all data groups can be modelled by using statistical distributions like gamma or lognormal distribution. In the study, the suitability of exponential, gamma, lognormal and Weibull distributions to observed data groups is tested by using Anderson-Darling test. The results are shown in Table 6. It is clear from the table, that for all groups of start response time data are in compliance with lognormal distribution. This result is consistent with the inferences of Koppa (2001).

Akçelik et al. (1999) assumed start response time as a constant value. However, analysis up to this point of the study has shown that when the leading driver makes a right or left turning manoeuvre or the leading driver is a female, start response time may be significantly different. On the other hand, there may be physical factors, which may affect the duration of start response time like lane width, cycle length, effective green time, etc.

The simplest method to have an idea on how different factors may affect start response time is performing a linear regression analysis. In this study the following parameters are chosen as independent variables in regression analysis:

- lane width 'LW' [m];

- red time 'RED' [sec];

- cycle time 'CYL' [sec];

- red/cycle time 'R/C';

- dummy variables:

- single lane approach ' $L S$ ', ( $L S=1$ for single-lane approach, otherwise 0 );

- manoeuvre type 'MNV', ( for through passing vehicles $M N V=0$, for right turning vehicles $M N V=1$ and for left turning vehicles $M N V=2)$;

- gender 'GN' ( $G N=1$ if the observed driver is male and ' 0 ' if the driver is female).

As the first step of model development, Pearson correlation test is performed for the parameters defined above as given in Table 7. It can be seen from the Table that, single lane approach $L S$ and lane width $L W$ parameters have no significant correlations with start response time. While manoeuvre type $M N V$, gender $G N$, red time $R E D$ and $\mathrm{red} /$ cycle time $R / C$ are significant at the 0.01 level and cycle length is significant at 0.05 level.

From the results presented in Table 7, manoeuvre type $M N V$, gender $G N$, red time $R E D$, cycle length $C Y L$ and red/cycle $R / C$ ratio values are used in a regression
Table 7. Correlations between start response time and considered parameters

\begin{tabular}{|l|l|c|c|}
\hline \multicolumn{2}{|c|}{ Variables } & $\begin{array}{c}\text { Pearson } \\
\text { correlation }\end{array}$ & Significance \\
\hline LS & Single-lane app. & -0.042 & 0.184 \\
\hline$M N V^{\star *}$ & Manoeuvre type & -0.160 & 0.000 \\
\hline$G N^{\star *}$ & Gender (male) & -0.137 & 0.000 \\
\hline LW & Lane width & 0.001 & 0.978 \\
\hline$R E D^{* *}$ & Red time & -0.121 & 0.000 \\
\hline$C Y L^{\star}$ & Cycle length & -0.054 & 0.038 \\
\hline$R / C^{* *}$ & Red/cycle ratio & -0.136 & 0.000 \\
\hline
\end{tabular}

Notes: ${ }^{*}$ correlation is significant at the 0.05 level (2-tailed);

${ }^{* *}$ correlation is significant at the 0.01 level (2-tailed).

analysis. The effects of these variables on start response time are investigated to combine them by means of multiple regression. $R E D, C Y L$ and $R / C$ parameters are highly correlated with each other, so their effects are tested in different regression models. The regression statistics of the final linear regression model given in Eq. (4) are presented in Table 8:

$$
t_{r}=-0.149 \cdot M N V-0.136 \cdot G N+0.020 \cdot C Y L .
$$

Table 8. Multiple regression statistics of manager type, gender, cycle length and lane width

\begin{tabular}{|l|c|c|c|c|c|c|}
\hline & $\beta$ & $\begin{array}{c}\text { Stan- } \\
\text { dard } \\
\text { error }\end{array}$ & $T$-statistic & $p$-value & $\begin{array}{c}\text { Lower } \\
\% 95\end{array}$ & $\begin{array}{c}\text { Upper } \\
\% 95\end{array}$ \\
\hline $\mathrm{MNV}$ & -0.149 & 0.036 & -4.171 & $3.29 \cdot 10^{-5}$ & -0.219 & -0.079 \\
\hline $\mathrm{GN}$ & -0.136 & 0.073 & -2.783 & & -0.278 & 0.006 \\
\hline $\mathrm{CYL}$ & 0.020 & 0.001 & 24.098 & $7.61 \cdot 10^{-102}$ & 0.018 & 0.022 \\
\hline
\end{tabular}

Notes: $R^{2}=0.703 ; S S=1973.54 ; M S=657.85 ; F$-value $=801.28$; $F_{\text {prob }}=4.6 \cdot 10^{-267}$.

From the Eq. (4) and Table 8 the following inferences can be made:

- male drivers have shorter response times than female drivers;

- drivers who will make a right or left turn, have relatively shorter response times than through passing drivers;

- longer cycle times may distract drivers' attention and lead them to respond to traffic signal change more slowly.

Table 6. Statistical distribution analysis of fit by distribution model

\begin{tabular}{|c|c|c|c|c|c|c|c|c|c|}
\hline \multirow{3}{*}{\multicolumn{2}{|c|}{ Manoeuvre type }} & \multicolumn{8}{|c|}{ Distribution } \\
\hline & & \multicolumn{2}{|c|}{ Lognormal } & \multicolumn{2}{|c|}{ Exponential } & \multicolumn{2}{|c|}{ Gamma } & \multicolumn{2}{|c|}{ Weibull } \\
\hline & & $\mathrm{AD}$ & $p$-value & $\mathrm{AD}$ & $p$-value & $\mathrm{AD}$ & $p$-value & $\mathrm{AD}$ & $p$-value \\
\hline \multirow{3}{*}{$\begin{array}{l}\text { Through } \\
\text { passing }\end{array}$} & male & 0.72 & 0.05 & 115.25 & $<0.003$ & 3.080 & $<0.005$ & 9.80 & $<0.010$ \\
\hline & female & 0.55 & 0.16 & 18.24 & $<0.003$ & 1.29 & $<0.005$ & 2.83 & $<0.010$ \\
\hline & all & 0.72 & 0.06 & 135.14 & $<0.003$ & 3.66 & $<0.005$ & 11.81 & $<0.010$ \\
\hline \multicolumn{2}{|c|}{ Left turning } & 0.52 & 0.18 & 34.75 & $<0.003$ & 1.50 & $<0.005$ & 5.47 & $<0.010$ \\
\hline \multicolumn{2}{|c|}{ Right turning } & 0.40 & 0.36 & 34.74 & $<0.003$ & 0.88 & 0.025 & 2.46 & $<0.010$ \\
\hline
\end{tabular}


These results are consistent with the previous results presented in Tables 4 and 5, and Figs 4 and 5.

The model presented in the Eq. (4) is tested by average start response time values observed at three different control intersections, which are not used in model development. Information of control intersections are given in Table 9. Response times for all nine intersections, which are used for model development and response times for three control intersections are calculated by using the Eq. (4). Averages of start response times for all drivers using each intersection are obtained and compared with the averages of observed response times (Fig. 6). From figure, it can be seen that suggested model can be used in determining average start response times at different signalized intersections.

Table 9. Information about the control intersections for model validation

\begin{tabular}{|l|c|l|c|c|}
\hline \multirow{2}{*}{$\begin{array}{c}\text { Name of the } \\
\text { intersection }\end{array}$} & $\begin{array}{c}\text { Volume } \\
{[\mathrm{veh} / \mathrm{h} / \mathrm{lane}]}\end{array}$ & $\begin{array}{c}\text { Approach } \\
\text { name }\end{array}$ & Lane type & $\begin{array}{c}\text { Cycle } \\
{[\mathrm{sec}]}\end{array}$ \\
\hline \multirow{2}{*}{ Yunuslar Int. } & 232 & \multirow{2}{*}{ Girne } & LT & \multirow{2}{*}{75} \\
\cline { 2 - 2 } & 197 & & $\mathrm{RT}$ & \\
\hline \multirow{2}{*}{ Çankaya Int. } & 1717 & \multirow{2}{*}{ Konak } & $2 \mathrm{TR}$ & \multirow{2}{*}{87} \\
\cline { 2 - 2 } \cline { 4 - 4 } & 1189 & & TR/RT & \\
\hline Anıt Int. & 312 & Konak & $2 \mathrm{TR}$ & 88 \\
\hline
\end{tabular}

\section{Discussion}

As explained in the introductory part, start response time has an important effect on saturation headway. By using Eqs (1) and (2), saturation flow of a lane at a signalized intersection can be predicted. The main problem is to choose an appropriate value for this calculation.

In this study, it is shown that start response time varies for different data sets and can be modelled by using lognormal distribution. Choosing a standard value for start response time may leads a traffic engineer to over or under design of signalization system.

In Fig. 7, comparison of base saturation flows with respect to different start response time values are shown. Eqs (1) and (2) are used in calculations. Acceleration delay and start-up lost time values in Eq. (1) are assumed as 2.7 and $2.0 \mathrm{sec}$ respectively.

By using the above assumptions, effects of gender and manoeuvre type on base saturation flow are also investigated. In Fig. 8, the effect of gender on saturation flow with respect to cycle time is shown. From this figure, it is clear that, a gender has more effect with short cycle lengths. However, two curves are relatively close to each other.

In literature, various models are used for calculation of adjustment factors of left and right turning vehicles. In Highway Capacity Manual (2010) adjustment factors for right and left turning vehicles are calculated by using the following equations:

$$
\begin{aligned}
& f_{R T}=\frac{1}{E_{R}} ; \\
& f_{L T}=\frac{1}{E_{L}} .
\end{aligned}
$$

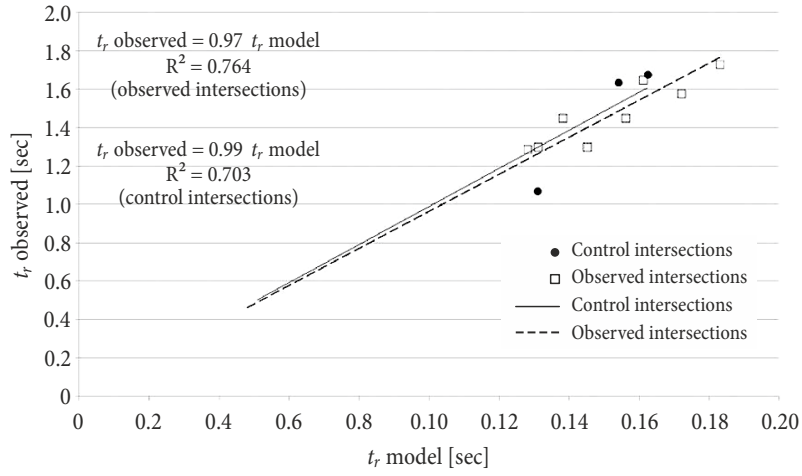

Fig. 6. Comparison of model results averages for each intersection with mean observed response times

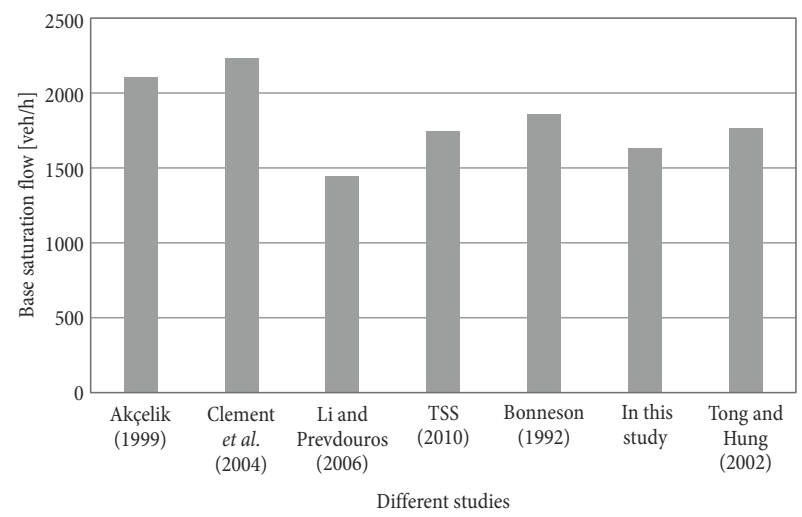

Fig. 7. Comparison of base saturation flows with respect to different start response time values

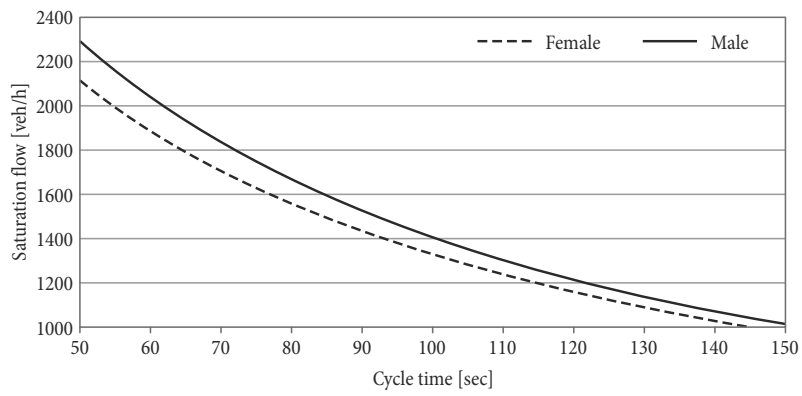

Fig. 8. Effect of gender on saturation flow

In the Eqs (5) and (6), $f_{R T}$ and $f_{L T}$ are the adjustment factors for right and left turning vehicles respectively. $E_{R}$ is the equivalent number of through cars for a protected right-turning vehicle and $E_{L}$ is the equivalent number of through cars for a protected left-turning vehicle. Here, start response times of left and right turning vehicles can be used in calculation of $E_{R}$ and $E_{L}$. This simply can be done for right turning vehicles by using the following formula:

$$
E_{R}=\frac{t_{r R T}+d_{a R T}-t_{s R T}}{t_{r T H}+d_{a T H}-t_{s T H}} .
$$

where: $t_{r R T}$ is the start response time of right turning vehicles; $d_{a R T}$ is the acceleration delay of right turning vehicles; $t_{s R T}$ is the start-up lost time of right turning vehicles; $t_{r T H}$ is the start response time of through pass- 
ing vehicles; $d_{a T H}$ is the acceleration delay of through passing vehicles; $t_{s T H}$ is the start-up lost time of through passing vehicles.

Our study only focuses on start response time values. Values of other factors are subject of different and/ or further research so they are not included in the study.

Results show that, driver behaviour has an important impact on signalized intersections performance as expected. However, the degree of influence is generally hard to comprehend. The easiest way is to reflect this difference by means of base saturation flows. For this purpose, the effect of using different base saturation flow values on performance parameters like delay and queue length of a traffic signal is analysed by using aaSIDRA 6.0 program. In the analyses, the following assumptions are made:

- traffic signal is a pedestrian signal which is located on a two-lane, one-way arterial;

- cycle time is assumed as 90-60 sec of cycle time are used by vehicles where remaining $30 \mathrm{sec}$ are used by pedestrians;

- traffic demand flow is assumed to change between 100-2200 veh/h/lane and pedestrian flow is assumed as $120 \mathrm{ped} / \mathrm{h}$;

- traffic flow is assumed to be formed of only through passing passenger cars;

- yellow and all red times are assumed as 3.0 and $2.0 \mathrm{sec}$ respectively;

- the grade of the system is negligible;

- no parking car nor bus stop exist;

- lane widths are assumed as $3.5 \mathrm{~m}$ each.

Analyses are carried-out in two stages:

- by assuming base saturation flow as $1950 \mathrm{veh} / \mathrm{h} /$ lane (default in aaSIDRA 6.0);

- by assuming base saturation flow as $1650 \mathrm{veh} / \mathrm{h} /$ lane (as calculated for through passing drivers' by using observed start response time values as shown in Fig. 7).

The results for delay values are shown in Fig. 10 (in the figure BSF is used for the term Base Saturation Flow).

From Fig. 9 it is clear that, when base saturation flow is assumed as $1650 \mathrm{veh} / \mathrm{h} / \mathrm{lane}$, under the same demand flow, system reaches its capacity much before when it is assumed as $1950 \mathrm{veh} / \mathrm{h} / \mathrm{lane}$ as expected. To put an emphasis on this outcome, the ratio of delays is plotted against traffic demand volumes in Fig. 9. In this figure, D1650 is the delay calculated for $1650 \mathrm{veh} / \mathrm{h} / \mathrm{lane}$ base saturation flow and D1950 is the delay calculated for $1950 \mathrm{veh} / \mathrm{h} /$ lane saturation flow value.

BSF of $1950 \mathrm{veh} / \mathrm{h} / \mathrm{lane}$ gives higher capacity and lower delay values for the same demand flow with BSF of $1650 \mathrm{veh} / \mathrm{h} / \mathrm{lane}$. This may lead an engineer to a signalization system under design. This is especially critical when degree of saturation reaches ' 1 ' (or system reaches its capacity). Drivers may experience up to 4 times longer delay values if the base saturation flow is not chosen properly (Fig. 10). In other words, if base saturation flow is chosen regardless of regional driver characteristics, a traffic facility will probably be over or under designed.

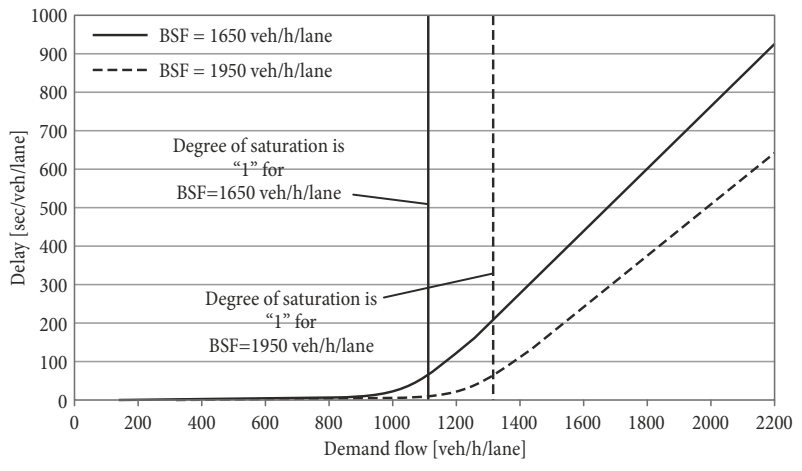

Fig. 9. Delay plots for $1650 \mathrm{veh} / \mathrm{h} / \mathrm{lane}$ and $1950 \mathrm{veh} / \mathrm{h} / \mathrm{lane}$ BSF values

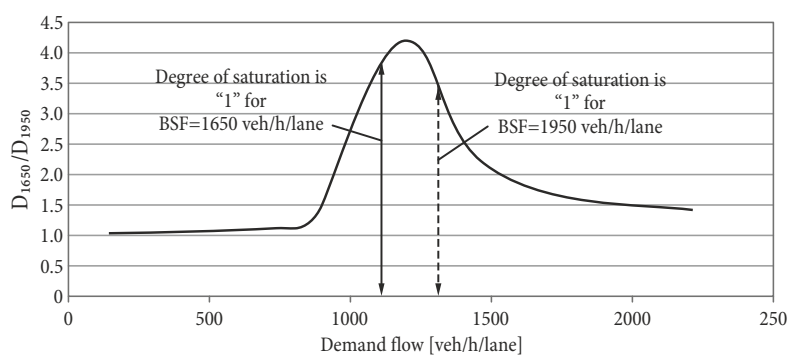

Fig. 10. $\mathrm{D}_{1650} / \mathrm{D}_{1950}$ plot with respect to traffic demand flow [veh/h/lane]

\section{Conclusions and Suggestions}

This study focuses on differences in drivers behaviour from start response time point of view. Start response time values of leading drivers in a queue at a traffic signal is tried to be analysed and discussed in detail.

It is known, that the queue discharge headways of leading vehicles expected to be higher than following vehicles' headways. This is probably because of the differences in start response time of the leading drivers. However, in contrast with general assumptions, using a constant value for start response time may not be appropriate.

Analysis showed that, male drivers have slightly shorter start response times than female drivers. This result agrees with the findings of Mehmood and Easa (2009). Thus, a gender is a demographic parameter like, age, income, education etc. In most cases, even complex mathematical models may fail to represent actual traffic conditions. At this point, adding demographic and physiological parameters may help researchers and engineers to understand better the traffic flow conditions. The results, obtained in this study, may be used in defining the difference between observations and model outcomes in analysis. They can also be used in traffic accident analysis at signalized intersections and calibration of micro simulation programs.

On the other hand, left and right turning drivers also have shorter start response times than all through passing vehicles. However, this result alone is not enough to make a judgment on the effect of left or right turning vehicles on intersection capacity. The reason why shorter start response times are observed for left and right turn- 
ing vehicles is probably because especially left turning drivers may experience longer waiting times. Thus, especially average start response times for left and right turning vehicles can be used in calculation of adjustment factors for left and right turns in saturation flow analysis. In future research, the relation between demographic characteristics of drivers and their response time can be investigated.

In accordance with previous findings, results of multi-regression analysis indicate that, start response time can be affected by the gender of the leading driver, manoeuvre type and cycle length.

However, driver characteristics such as vehicle following habits, lane discipline and precision on traffic rules and driving characteristics like aggressiveness and calmness greatly affect headways and start response time of drivers. Therefore, physiological parameters should be taken into consideration in headway and start response time analysis along with the parameters stated above. This point of view can be tested in further research studies.

One of the most important outcomes of this study is choosing a base saturation flow in analysis regardless of regional driver characteristics probably lead an engineer to over or under designs a traffic facility. Further researches which contain site-specific driver behaviour characteristics like start response time should be carried-out to overcome this flaw.

\section{References}

Akçelik, R.; Besley, M.; Roper, R. 1999. Fundamental Relationships for Traffic Flows at Signalised Intersections. Research Report ARR 340. ARRB Transport Research Ltd., Vermont South, Australia. $194 \mathrm{p}$.

Bonneson, J. A. 1992. Modeling queued driver behavior at signalized junctions, Transportation Research Record: Journal of the Transportation Research Board 1365: 99-107.

Calışkanelli, S. P. 2010. Sinyalizasyon Sistemlerinden Ayrılan Araçların Takip Aralı̆̆ Dağılımının İncelenmesi: Doktora Tezi. Dokuz Eylül Üniversitesi, Fen Bilimleri Enstitüsü. 130 s. Available from Internet: http://acikerisim.deu.edu.tr/xmlui/bitstream/handle/12345/9204/283662.pdf (in Turkish).

Clement, S. J.; Taylor, M. A. P.; Yue, W. L. 2004. Simple platoon advancement: a model of automated vehicle movement at signalized intersections, Transportation Research Part C: Emerging Technologies 12(3-4): 293-320. http://doi.org/10.1016/j.trc.2004.07.012

Highway Capacity Manual. 2010. Transportation Research Board. 5th edition. $1650 \mathrm{p}$.

ITE. 1994. Determination of Vehicle Signal Change and Clearance Intervals. Publication IR-073. An Informational Report of the Institute of Transportation Engineers (ITE). Washington, DC. 16 p.

Jin, X.; Zhang, Y.; Wang, F.; Li, L.; Yao, D.; Su, Y.; Wei, Z. 2009. Departure headways at signalized intersections: a log-normal distribution model approach, Transportation Research Part C: Emerging Technologies 17(3): 318-327.

http://doi.org/10.1016/j.trc.2009.01.003

Koppa, R. J. 2001. Human factors, in N. H. Gartner, C. J. Messer, A. K. Rathi (Eds.). Traffic Flow Theory: A State-of-theArt Report, 3-1-3-32.
Li, H.; Prevedouros, P. 2002. Detailed observations of saturation headways and start-up lost times, Transportation Research Record: Journal of the Transportation Research Board 1802: 44-53. http://doi.org/10.3141/1802-06

Long, G. 2005. Start-up delays of queued vehicles, Transportation Research Record: Journal of the Transportation Research Board 1934: 125-131. http://doi.org/10.3141/1934-13

Luttinen, R. T. 1996. Statistical Analysis of Vehicle Time Headways: Dissertation for the degree of Doctor of Technology. Helsinki University of Technology, Finland. 193 p. Available from Internet: http://lib.tkk.fi/Diss/199X/isbn951228474X/ isbn951228474X.pdf

Mehmood, A.; Easa, S. M. 2009. Modeling reaction time in car-following behaviour based on human factors, International Journal of Civil, Environmental, Structural, Construction and Architectural Engineering 3(9): 325-333.

Messer, C. J.; Fambro, D. B. 1977. Effects of signal phasing and length of left-turn bay on capacity, Transportation Research Record: Journal of the Transportation Research Board 644: 95-101.

Qu, X.; Zhang J.; Liu Z. 2014. Modelling follow up time at a single-lane roundabout, Journal of Traffic and Transportation Engineering (English Edition) 1(2): 97-102. http://doi.org/10.1016/S2095-7564(15)30093-3

Roess, P. R.; Prassas, E. S.; McShane, W. R. 2010. Traffic Engineering. 4th edition. Pearson. $744 \mathrm{p}$.

SIRC. 2004. Sex Differences in Driving and Dnsurance Risk: an Analysis of Social and Psychological Differences Between Men and Women that are Relevant to Their Driving Behaviour. Social Issues Research Centre (SIRC). 24 p. Available from Internet: http://www.sirc.org/publik/driving.pdf

Sivak, M; Schoettle, B. 2011. Toward understanding on-road interactions of male and female drivers, Traffic Injury Prevention 12(3): 235-238.

http://doi.org/10.1080/15389588.2011.562945

Tong, H. Y.; Hung, W. T. 2002. Neural network modeling of vehicle discharge headway at signalized intersection: model descriptions and results, Transportation Research Part A: Policy and Practice 36(1): 17-40. http://doi.org/10.1016/S0965-8564(00)00035-5

TSS. 2010. Aimsun 6.1 Users' Manual. Transport Simulation Systems (TSS) 2005-2010. Available from Internet: http:// www.aimsun.com 